international superagency to provide the necessary leadership, direction, and coordination of efforts.

Gary R. Leff

Menomonie, Wis

\section{Economic Snake Oil}

To the Editors: Excursus I "The Ethics of Economic Ignorance") of Worldview, April, 1975, is a statement by one PLB, who must be the Peter L. Berger whose name appears upon the back cover of the issue. Mr. Berger states that there is disagreement between two groups of connomists regarding treatment of the current economic crisis. The classical group, the adherents of "the old time religion." favor allowing recession to take its course. The Keynesian group, the "purveyors of snake oil," wish to relieve the growing unemployment by deliberate inflation.

PLB prociaims that he, like the ordinary citizen, is an economic ig. noramus. But, by implication, he does admit to mastery of ethics, and states an ethical championship of inflation by an ethical maxim: "If one is ignorant of the consequences of two possible courses of action, one should take the course that is less cruel now. This is a rather elementary maxim of medical ethics. It is no less applicable to economis policy."

I cannot subscribe to Mr. Berger's analogy. By extension I question whether his espousal of the short-term good as against a more important longer-term evil is ethically sound.

A patient has a severe abdominal pain of unknown cause. Short-term, his pain (evil) $c$ an be relieved simply and easily by an adequate narcotic injection. Everyone, including the patient, can happily go to sleep. Meantime, masked by the narcotic, the distended appendix which, by increasing distress could have been diagnosed and removed, ruptures. The short-term good has resulted in a prolonged and serious illness, or death.

Another patient has accidentsily found a painless lump in her breast. It could be an innoctrous collection of fluid. It could be a potentiatly fatal cancer. Why not avoid the cruelty of a surgical violation of the body's integrity and a possible permanent mutila. tion? The less crael course has often resulted in much more serious evil and, depending upon the real character and extent of the discase, has robbed this patient of at worst 30 per eent and at best 85 per cent of her otherwise normal life expectancy

There is a more cynical viewpoint which should appes to Mr. Berger. It is conceivable that a few of his liberal inflationists are hoping that their rem. edy will lead inevitably to the chaos of total collapse and a probable Marxian solution. They are Mr. Hyde. Dr. Jekyll would favor the short-term cruelty of the knife

PLB indulges in another misleading appeal: "8 per cent unemployment represents a mass of human misery far greater than that represented by 11 per cent inflation." In the first place. 8 per cent unemployment is a fact that exists in the present actuality of 11 per cent inflation. A therapeutic dose of shor-term narcotic obviously must be far greater than 11 per cent. And, second, the misery of the unermployed 8 per cent should not be measured against the mathematical abstraction of 11 per cent inflation, but against the equally nonmeasurable misery of a group much larger: the aged, the pen. sioners, those who depend upon insurence measured in dollars of vanishing value, the credulous savers who had hoped to provide for their nonproductive years.

I suggesi an alternate conclusion to Mr. Berger: that he refrain from ced. ing his case to the liberals until he can refrain from equating apples with numbers instead of turnips; that he restudy medical ethics, and even ethics. Francis H. Straus, M.D.

\section{Chicago, III.}

To the Editors: Professor Peter Berger's attempt to be ethical in his economics while being ignorant of economics fails. His effort fails because his solution assumes the know]. edge he admits to lack.

Berger would exchange government spending in an attempt to reduce unemployment in exchange for more inflation. The justiffcation of this moral preference requires scales on which to weigh the relative miseries produced by ' anemployment and inflation. No one has such scales.

The physiologist Claude Bernard once told us that in ignorance it is wiser to refrain than to recommend.

Gwynn Nettler

Department of Sociology

University of Alberia

Edmonton, Canada

\section{Kurdish Refugees}

To the Editors: A number of Worldview articles have been devoted to the plight of refugees, but there has been almost no reference to the Kurds. This four thousand-year-old race of people has been sold out, betrayed, and defeated in their fight for survival as an autonomous nation. Hoping to achieve self-determination, as promised to them in the Treaty of Sevrès after World War $I_{\text {, the Kurdish people }}$ have instead become victims of the brutal politics of an aggressive power struggle. As their refugees die by the thousands at closed borders and their very existence faces annihilation, the silence of our press and our news networks is not only puzzling, it is an outrage to our pretensions to conscience and consciousness.

This is not a civil war; nor can these people be brushed off as "dissidents" or "rebels." The history of Kurdistan goes back to the Sumerians in $\mathbf{2 0 0 0}$ B.c., since which time the Kurds have occupied some 150,000 square miles. After World War I that area was divided between Turkey, Persia, Syria and Irag. At the same time, the Kurds were promised the right of selfdetermination as were Jews and Arab successor nations to the Ottoman $\mathrm{Em}$ pire. But imperialistic power struggles and oil fields darkened the future of the estimated ten million Kurds in this area. In Iraq the two million Kurds, a nonaggressive people by nature, have been fighting somewhat successfully in their attempt to hold their homes, their lives, their culture. In 1974 the Shat of Iran gave full support to the Iraqi Kurds. Irag's artventurous foreign policy and growing links with the Soviet Union made the Shah fear for his own (Confinued on p. 59) 